\title{
Pharmacological LRH-1/Nr5a2 inhibition limits pro- inflammatory cytokine production in macrophages and associated experimental hepatitis
}

Juliane Schwaderer ${ }^{1}$, Truong San Phan $\mathbb{D}^{1}$, Astrid Glöckner ${ }^{1}$, Johannes Delp $\mathbb{B}^{2,3}$, Marcel Leist $\mathbb{C}^{2}$, Thomas Brunner ${ }^{1}$ and M. Eugenia Delgado (iD ${ }^{1}$

\begin{abstract}
Liver receptor homolog-1 ( $\mathrm{LRH}-1, \mathrm{Nr} 5 \mathrm{a} 2)$ is an orphan nuclear receptor mainly expressed in tissues of endodermal origin, where its physiological role has been extensively studied. LRH-1 has been implicated in liver cell differentiation and proliferation, as well as glucose, lipid, and bile acid metabolism. In addition, increasing evidence highlights its role in immunoregulatory processes via glucocorticoid synthesis in the intestinal epithelium. Although the direct function of $\mathrm{LRH}-1$ in immune cells is fairly elucidated, a role of $\mathrm{LRH}-1$ in the regulation of macrophage differentiation has been recently reported. In this study, we aimed to investigate the role of $\mathrm{LRH}-1$ in the regulation of pro-inflammatory cytokine production in macrophages. Our data demonstrate that pharmacological inhibition, along with $\mathrm{LRH}-1$ knockdown, significantly reduced the lipopolysaccharide (LPS)-induced production of pro-inflammatory cytokines in the macrophage line RAW 264.7 cells, as well as in primary murine macrophages. This inhibitory effect was found to be independent of defects of LRH-1-regulated cell proliferation or toxic effects of the LRH-1 inhibitors. In contrast, LRH-1 inhibition reduced the mitochondrial ATP production and metabolism of macrophages through downregulation of the LRH-1 targets glucokinase and glutminase-2, and thus impairing the LPS-induced macrophage activation. Interestingly, in vivo pharmacological inhibition of LRH-1 also resulted in reduced tumor necrosis factor (TNF) production and associated decreased liver damage in a macrophage- and TNF-dependent mouse model of hepatitis. Noteworthy, despite hepatocytes expressing high levels of $\mathrm{LRH}-1$, pharmacological inhibition of $\mathrm{LRH}-1$ per se did not cause any obvious liver damage. Therefore, this study proposes $\mathrm{LRH}-1$ as an emerging therapeutic target in the treatment of inflammatory disorders, especially where macrophages and cytokines critically decide the extent of inflammation.
\end{abstract}

\section{Introduction}

The liver receptor homolog-1 (LRH-1/Nr5a2) belongs to the Ftz-F1 subfamily of nuclear receptors and is predominantly expressed in enterohepatic tissues of both,

\footnotetext{
Correspondence: M. Eugenia Delgado (eugenia.delgado@uni-konstanz.de) ${ }^{1}$ Biochemical Pharmacology, Department of Biology, University of Konstanz, Konstanz, Germany

${ }^{2}$ In Vitro Toxicology and Biomedicine, inaugurated by the DoerenkampZbinden Foundation, Department of Biology, University of Konstanz, Konstanz, Germany

Full list of author information is available at the end of the article. These authors contributed equally: Thomas Brunner, M. Eugenia Delgado Edited by G. Amarante-Mendes
}

human, and murine organisms. Here, it is crucially involved in the transcriptional control of different physiological processes, including maintenance of stemness, proliferation, metabolism, and steroidogenesis ${ }^{1}$. In the liver LRH-1 controls bile acid synthesis, lipid, and glucose metabolism ${ }^{2-6}$, whereas in the intestinal epithelium it is involved in the control of stem cell proliferation and selfrenewal through the transcriptional regulation of cyclin D1 and E1 ${ }^{7}$. Moreover, LRH-1 controls the synthesis of immunoregulatory glucocorticoids via the expression of the steroidogenic enzymes Cyp11b1 and Cyp11a1 in the intestinal epithelium, implicating this nuclear receptor in

\section{(c) The Author(s) 2020}

(c) (i) Open Access This article is licensed under a Creative Commons Attribution 4.0 International License, which permits use, sharing, adaptation, distribution and reproduction in any medium or format, as long as you give appropriate credit to the original author(s) and the source, provide a link to the Creative Commons license, and indicate if changes were made. The images or other third party material in this article are included in the article's Creative Commons license, unless indicated otherwise in a credit line to the material. If material is not included in the article's Creative Commons license and your intended use is not permitted by statutory regulation or exceeds the permitted use, you will need to obtain permission directly from the copyright holder. To view a copy of this license, visit http://creativecommons.org/licenses/by/4.0/. 
the regulation of the local immune homeostasis ${ }^{8,9}$. Recently, evidence for a more direct role of LRH-1 in the control of immune cell differentiation and function has been reported. Thus far, the function of LRH-1 in immune cells has been largely ignored, mostly due to its remarkably lower expression levels when compared with endodermal tissues. While Benod et al. ${ }^{10}$ first reported the coincidental observation of LRH-1 expression in tumorinfiltrating immune cells in pancreatic tumor tissues, Lefevre et al. ${ }^{11}$ provided first evidence of the relevance of LRH-1 in cells from the hematopoietic compartment, that is, macrophages. In this study, the authors demonstrated that LRH-1 controls interleukin-13 (IL-13)-induced macrophage polarization via the Cypla1- and Cypb1regulated production of the peroxisome proliferatoractivated receptor- $\gamma$ ligand 15-HETE (15-hydroxyeicosatetraenoic acid), highly impacting the differentiation of macrophages towards an anti-inflammatory and anti-fungal M2 phenotype ${ }^{11}$.

Although the role of LRH-1 in cells from hematopoietic cells is mostly unexplored, its expression appears not to be restricted to the macrophage lineage. We previously have shown that immature and mature $\mathrm{T}$ cells express LRH-1, which is further induced upon T cell activation ${ }^{12}$. A more recent publication highlights the critical role of $\mathrm{LRH}-1$ in $\mathrm{T}$ cell maturation and functions ${ }^{13}$. Specific depletion of LRH-1 in T cells strongly reduced their activation-induced proliferation, resulting in the impaired induction of $\mathrm{T}$ cell-regulated immune responses ${ }^{13}$. Importantly, we identified the tumor necrosis factor (TNF) family member Fas ligand (FasL, CD95L) as an LRH-1-regulated target gene ${ }^{12}$. Pharmacological inhibition of LRH-1 not only resulted in reduced activationinduced FasL transcription and protein expression but also in attenuated FasL-mediated effector functions in $\mathrm{T}$ cells, such as cell-mediated cytotoxicity and activationinduced cell death. Critically, pharmacological inhibition of LRH-1 also decreased the concanavalin A-induced FasL expression in vivo, resulting in a strong protection from FasL-mediated liver cell apoptosis and associated hepatitis $^{12}$. These studies not only demonstrate the presence and relevance of LRH-1 in the immune cell activation and effector function of hematopoietic cells but they also suggest this nuclear receptor as an interesting therapeutic target in the treatment of immunopathological diseases.

In this study, we investigated the role of LRH-1 in the regulation of lipopolysaccharide (LPS)-induced proinflammatory cytokines in macrophages and in an in vivo model of macrophage- and TNF $\alpha$-dependent hepatitis. Our results demonstrate that inhibition of LRH1 with two unrelated pharmacological inhibitors significantly reduced LPS-induced pro-inflammatory cytokine production in the macrophages cell line RAW 264.7, as well as in primary bone marrow-derived macrophages
(BMDMs), liver-resident macrophages (Kupffer cells), and even human peripheral blood mononuclear cell (PBMC)derived monocytes. While LRH-1 inhibition did not appear to impair macrophage survival or proliferation, we noticed a profound decrease in glutamine- and glucosemetabolizing enzymes at the transcriptional level, leading to decreased mitochondrial activity and impairment in metabolism, ultimately resulting in reduced production of pro-inflammatory cytokines. Importantly, pharmacological inhibition of LRH-1 was also able to significantly inhibit LPS-induced TNF production in vivo, thus preventing $\mathrm{LPS} / \mathrm{N}$-acetyl-D-galactosamine $(\mathrm{GalN})$-induced, TNF-mediated, acute hepatitis in mice. These results provide further evidence for a critical role of LRH-1 in the regulation of immune cells, in particular macrophages, and support the notion of LRH-1 as a novel and interesting pharmaceutical target in the treatment of immunopathological disorders, such as immune cell-mediated hepatitis.

\section{Results \\ LRH-1 regulates activation-induced TNF production in splenocytes}

While in the intestine LRH-1 activity has been associated with anti-inflammatory properties, for example, via the production of immunoregulatory glucocorticoids, more recent studies proposed a novel and more direct role of LRH-1 in the regulation of immune cell differentiation and effector functions ${ }^{11-13}$. Given that activated macrophages are a rich source of cytokines implicated in the initiation of inflammatory responses, we aimed to investigate the effect of pharmacological inhibition of LRH-1 in the activation-induced production of proinflammatory cytokines.

We first assessed the levels of LRH-1 in macrophages and associated tissue samples. Indeed, $\mathrm{Nr} 5 \mathrm{a} 2$ messenger RNA (mRNA) was detected at high levels in the liver and also in spleen cells, as well as in BMDMs and in the macrophage cell line RAW 264.7, although at considerably lower expression levels (Fig. 1a). RAW 264.7 cells showed a clear endogenous LRH-1 transcriptional activity as measured by an LRH-1 activity luciferase reporter ${ }^{14}$, which was significantly reduced by the LRH-1 inhibitor $3 \mathrm{~d} 2$ (Fig. 1b). $3 \mathrm{~d} 2$ is a small inhibitor identified in a chemical screen and has been shown to directly bind to the ligandbinding domain of this nuclear receptor, stabilizing its inactive conformation and hence selectively preventing its transcriptional activity ${ }^{15}$. We next investigated the role of LRH-1 in activation-induced cytokine expression in macrophage containing murine splenocytes. Their stimulation with LPS resulted in the release of the pro-inflammatory cytokine TNF, which was dose dependently inhibited by $3 \mathrm{~d} 2$ (Fig. 1c). Thus, these data confirm the fact that LRH-1 is expressed and active in macrophages, and that its 

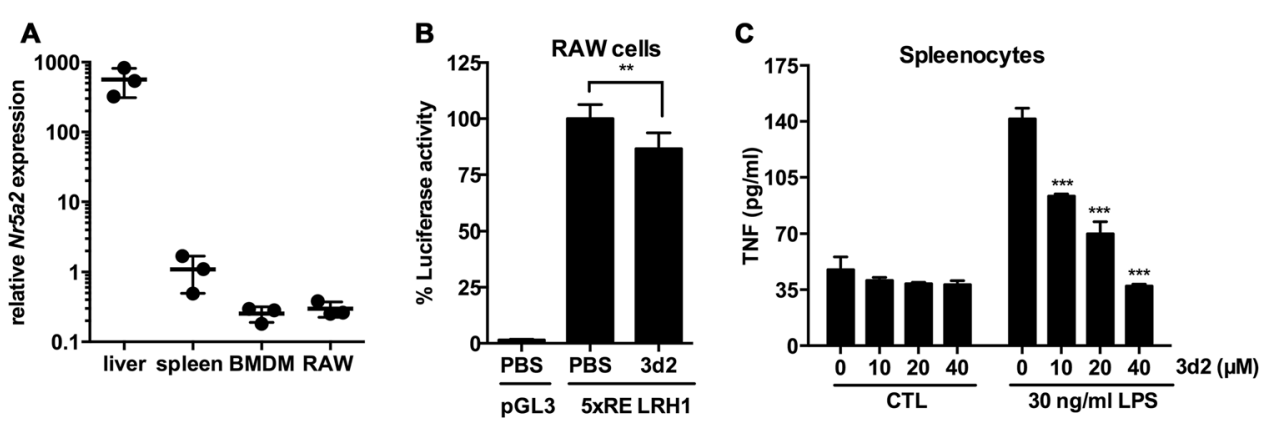

Fig. 1 LRH-1 expression and activity in macrophages. a Relative Nr5a2 mRNA expression in the liver, spleen, and bone marrow-derived macrophages (BMDM) from wild-type C57BL/6 mice, as well as in the macrophage cell line RAW 264.7 (RAW). Results are shown as relative to murine Gapdh mRNA expression. Mean values (bars) and individual data points from three mice, resp. cell samples, per group are shown. b Endogenous LRH1-dependent transcriptional activity in RAW 264.7 cells. Cells were transfected with the LRH-1 luciferase reporter construct (5 $\times$ RE LRH-1) or an empty luciferase reporter (pGL3) and treated with vehicle (PBS) or $3 \mathrm{~d} 2(40 \mu \mathrm{M})$. Mean values of triplicates \pm SD of two independent experiments are shown. Luciferase activity was normalized to untreated cells ( $t$ test; ${ }^{* *} p<0.01$ ). c TNF protein levels measured in the supernatant of splenocytes from wildtype C57BL/6 mice and pre-treated for $2 \mathrm{~h}$ with indicated concentrations of $3 \mathrm{~d} 2$, prior to stimulation with control buffer (CTL) or LPS ( $30 \mathrm{ng} / \mathrm{ml})$. Mean values of triplicates \pm SD of a representative experiment $(n=3)$ are shown (one-way ANOVA, ${ }^{* * *} p<0.001$ ).

pharmacological inhibition impacts LPS-induced TNF production in splenic macrophages.

\section{LRH-1 inhibition reduces the pro-inflammatory cytokine production in RAW 264.7 cells}

We next aimed to analyze the role of LRH-1 in macrophages more directly. RAW 264.7 cells stimulated with LPS strongly induced the transcription of the proinflammatory cytokines TNF, IL-6, and IL-1 $\beta$, even at low concentrations of LPS (Fig. 2a-e). Supporting our experiments with splenocytes, a significant inhibition of LPS-induced Tnf, Il6, and $I l 1 b$ transcripts was strongly attenuated after pharmacological inhibition of LRH-1 by $3 \mathrm{~d} 2$ (Fig. $2 \mathrm{a}-\mathrm{c}$ ). In line with reduced transcription, also the LPS-induced release of TNF and IL- 6 proteins were dose dependently inhibited by $3 \mathrm{~d} 2$ (Fig. $2 \mathrm{~d}$, e). In order to further confirm the results obtained with $3 \mathrm{~d} 2$, we also employed an alternative LRH-1 inhibitor, the SR1848 ${ }^{16}$. Similarly, SR1848 also dose dependently inhibited the LPS-induced release of TNF in RAW 264.7 cells (Fig. 2f), thus further confirming the role of LRH-1 activity in macrophage-dependent cytokine production.

In addition, we employed RNA interference-mediated downregulation of LRH-1 in order to demonstrate the specificity of the LRH-1 inhibitors on LPS-induced cytokine production in macrophages. Confirming the effect of the pharmacological inhibition, LRH-1 downregulation by short hairpin RNA (shRNA) against $N r 5 a 2$ (Fig. 2g) also resulted in a reduction of the LPS-dependent release of TNF respect untargeted controls (Fig. 2h).

\section{LRH-1 inhibition impairs LPS-induced cytokine production BMDMs and Kupffer cells}

As RAW 264.7 is a cell line derived from virustransformed murine peritoneal macrophages and therefore certain pathways and associated phenotype might not be representative for untransformed cells, we extended our studies to primary macrophages. Comparable to RAW 264.7 cells, 3d2-pre-treated macrophages generated from murine BMDM showed a strong reduction of LPSdependent TNF and IL-6 induced (Fig. 3a, b). While RAW 264.7 cells failed to release IL-1 $\beta$ in response to LPS (data not shown), BMDMs produced and released IL-1 $\beta$ protein, which was also attenuated by LRH-1 inhibition (Fig. 3c). Similarly, murine ex vivo LPS stimulation of isolated liver-resident macrophages (Kupffer cells) also resulted in increased TNF release, which was also inhibited by 3d2 (Fig. 3d). Interestingly, a similar effect was observed in primary human PBMCs. Confirming previous results in primary murine macrophages, $3 \mathrm{~d} 2$ treatment also resulted in a decreased LPS-induced TNF production by monocytes (Supplementary Fig. 1).

In order to further support the role of LRH-1 in the regulation of macrophage activation, we generated BMDMs from small heterodimer partner (SHP, NrOb2)deficient mice. The nuclear receptor SHP is a transcriptional target and at the same time inhibitor of LRH-1 $1^{17,18}$. In line with pharmacological inhibitors or LRH-1 downregulation, we observed increased LPS-induced TNF production in SHP-deficient macrophages compared to that in wild-type macrophages (Fig. 3e), suggesting that in the absence of SHP inhibition, a higher LRH-1 transcriptional activity results in an increased macrophage activation and TNF production.

\section{LRH-1 activity regulates mitochondrial metabolism in macrophages}

In line with the hypothesis of impaired LPS-mediated activation, 3d2-treated RAW 264.7 cells did not show the typical morphology of activated macrophages upon LPS 

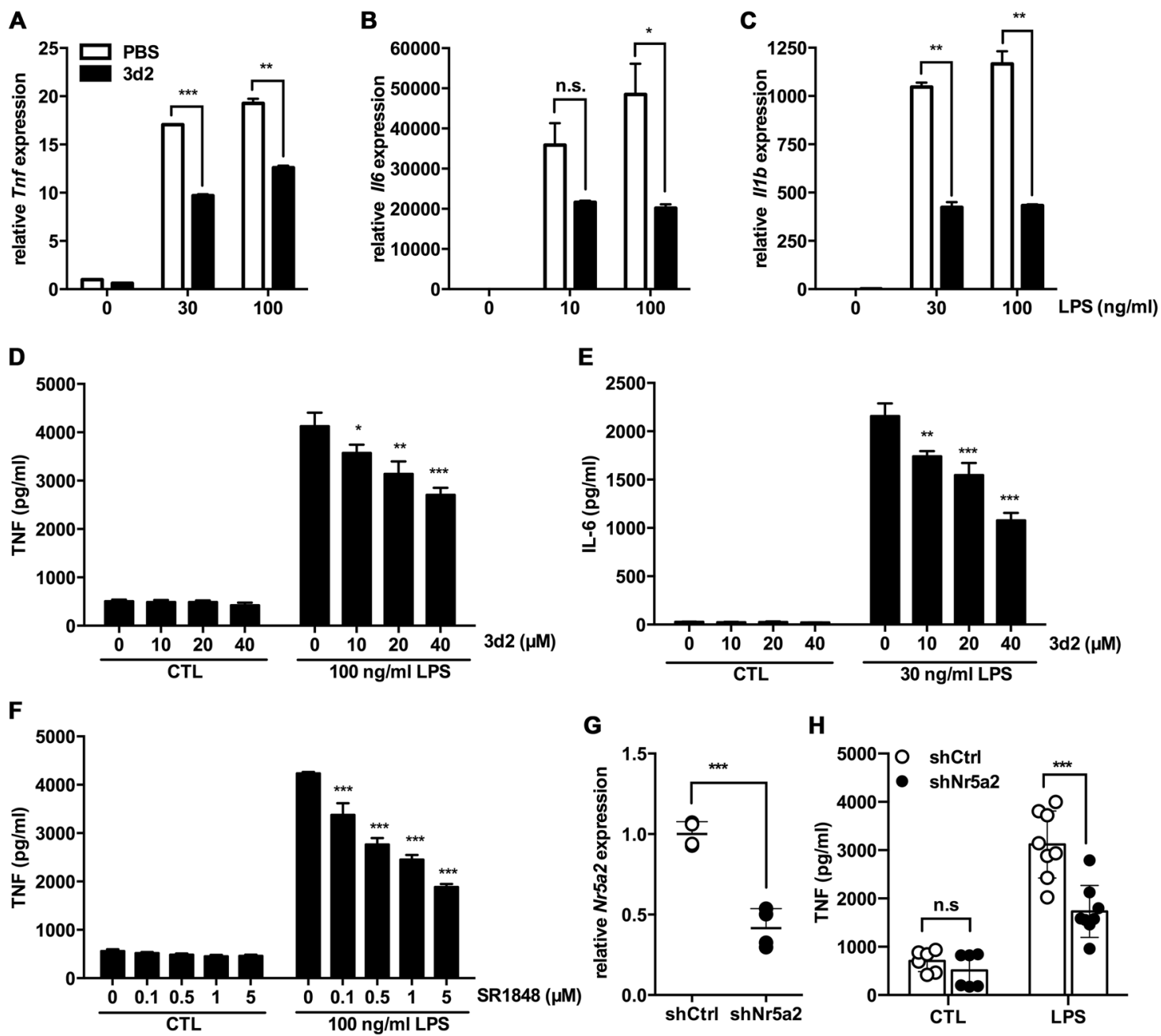

Fig. 2 LRH-1 inhibition reduces the pro-inflammatory cytokine production in LPS-stimulated RAW 264.7 cells. mRNA expression levels of a Tnf, b $\| 6$, and $\mathbf{c} \| 16$ in RAW 264.7 cells pre-treated for $2 \mathrm{~h}$ with vehicle (PBS) or $3 \mathrm{~d} 2(40 \mu \mathrm{M})$ and subsequently stimulated with control buffer (CTL) or LPS at indicated concentrations for $18 \mathrm{~h}$. Results are shown as relative to murine Gapdh mRNA expression. Mean values of triplicates \pm SD of three independent experiments are shown ( $t$ test; ${ }^{* *} p<0.01,{ }^{* * *} p<0.001$ ). $\mathbf{d}$ TNF and $\mathbf{e} \mathrm{IL}-6$ secreted levels in the supernatant of RAW 264.7 cells pretreated with indicated concentrations of $3 \mathrm{~d} 2$ for $2 \mathrm{~h}$ and subsequently stimulated with control buffer (CTL) or LPS at indicated concentrations for $18 \mathrm{~h}$. f TNF secreted levels in the supernatant of RAW 264.7 cells pre-treated for $2 \mathrm{~h}$ with SR1848 at indicated concentrations, prior to stimulation with control buffer (CTL) or LPS at indicated concentrations for $18 \mathrm{~h}$. Mean values of triplicates \pm SD of a representative experiment $(n=3)$ are shown (oneway ANOVA, $\left.{ }^{*} p<0.05,{ }^{* *} p<0.01,{ }^{* * *} p<0.001\right)$. g Quantification of mRNA levels of Nr5a2 in RAW 264.7 cells transduced with shRNA against Nr5a2 (shNr5a2) or shRNA control (shCtrl). Data are shown as relative to murine Actb mRNA and expressed as fold change to shCtrl cells. $\mathbf{h}$ TNF produced in RAW 264.7 cells transduced with shNr5a2 or shCtrl control and subsequent treated with control buffer (CTL) or LPS ( $30 \mathrm{ng} / \mathrm{mL})$ for $18 \mathrm{~h}$. Dots show technical replicates and bars means \pm SD of data pooled from two independent experiment (two-way ANOVA, ${ }^{*} p<0.05,{ }^{* *} p<0.01,{ }^{* * *} p<0.001$, n.S., not significant).

stimulation. This morphology consist of extensive cell spreading or lamellipodia on the leading edge of the cells $^{19}$ (Fig. 4a). This suggested that LRH-1 inhibition results in reduced macrophage activation, ultimately resulting in reduced cytokine production.

$\left[{ }^{3} \mathrm{H}\right]$ thymidine incorporation assays showed no obvious inhibition of proliferation in RAW 264.7 cells treated with different concentrations of $3 \mathrm{~d} 2$ (Fig. 4b), disregarding the hypothesis that the 3d2-dependent effect in cytokine production might be due to a reduced cell proliferation after pharmacological LRH-1 inhibition, as observed previously $^{13}$. Moreover, neither 3d2 nor SR1848 inhibitor had direct cytotoxic effects in RAW 264.7 cells, as analyzed by AnnexinV staining and flow cytometry (Fig. 4c), or by the propidium iodide (PI)/Hoechst dye-stained ratio $(\mathrm{H} 33342)^{20}$ (Fig. 4d). Interestingly though, when cell viability was monitored with the MTT (3-(4,5-dimethylthiazol-2-yl)-2,5-diphenyltetrazolium bromide assay, RAW 264.7 cells treated with $3 \mathrm{~d} 2$ showed a dose-dependent decrease in general mitochondrial activity as documented 


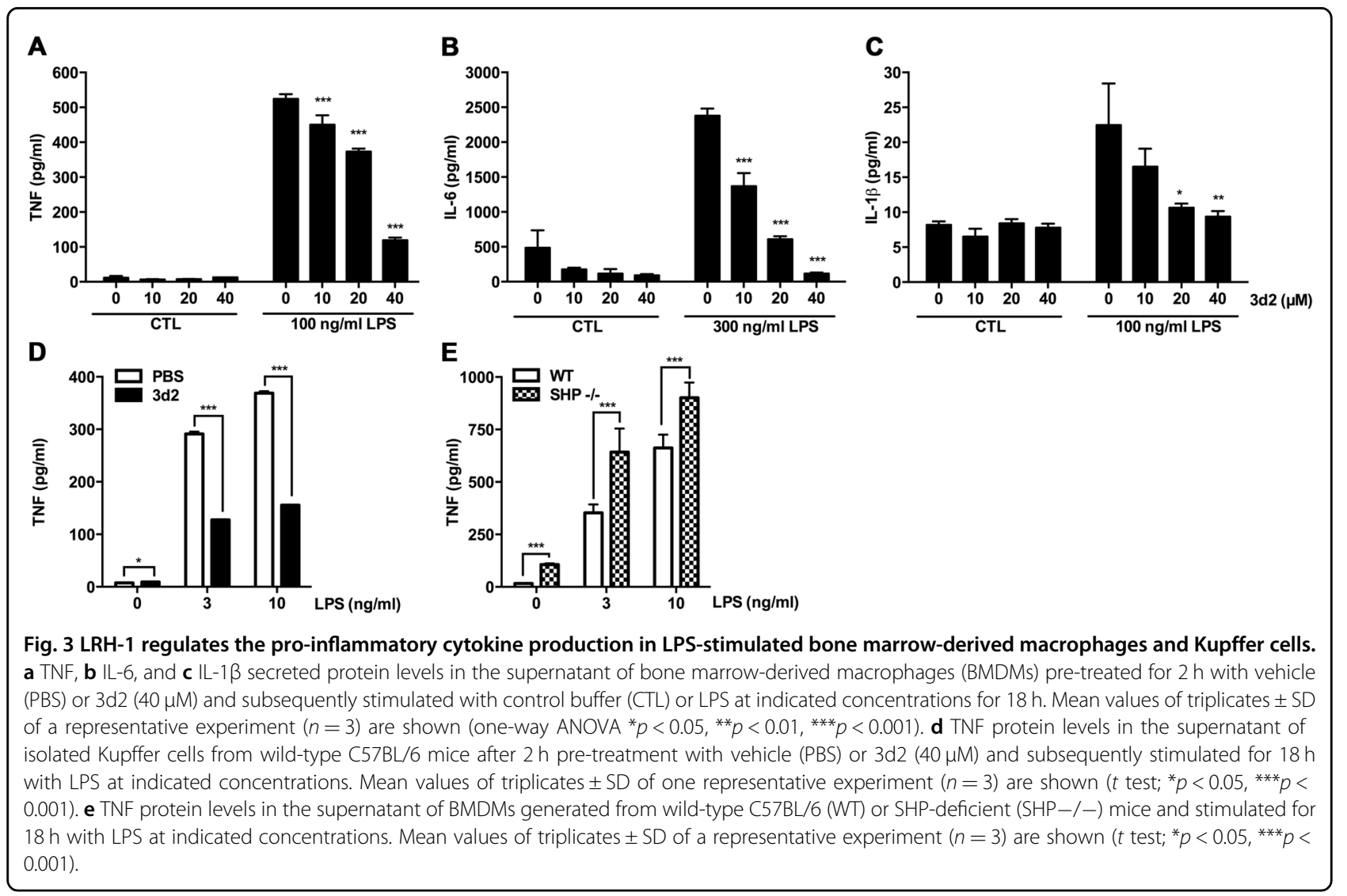

by the reduced production of the MTT metabolite, the insoluble formazan salt (Fig. 4e). Indeed, besides regulating cell cycle progression and proliferation, LRH-1 has been involved in the control of mitochondrial function and metabolic processes ${ }^{1-3,21,22}$. In line with this notion, RAW 264.7 cells exposed to increasing concentrations of 3d2 showed a significant decrease in cellular ATP levels (Fig. 4g). Thus, LRH-1 activity may also regulate mitochondrial metabolism in macrophages. Interestingly, this hypothesis could be confirmed by the shRNA-mediated downregulation of LRH-1 (Fig. 2g). In this case, shRNA against $\mathrm{Nr} 5 \mathrm{a} 2$ resulted also in a decrease in MTT activity (Fig. 4f) and in ATP levels (Fig. 4h), when compared to untargeted controls.

In the liver, LRH-1 has been described as a critical transcriptional regulator of the mitochondrial glutaminase-2 enzyme (Gls2), greatly impacting on the glutamine-induced metabolic signaling pathway in hepatic cancer cells ${ }^{2}$. Similarly, LRH-1-dependent regulation of glucokinase (Gck) has been described to tightly control liver glucose sensing and processing, since Gck is the enzyme responsible for catalyzing the first step of glycolysis $^{3}$. In line with the role of LRH-1 in regulating these gene products, we observed reduced levels of Gck and Gls2 transcripts in RAW 264.7 cells exposed to $3 \mathrm{~d} 2$ (Fig. 4i). Similarly, downregulation of LRH-1 resulted in reduced levels of the LRH-1 targets $\mathrm{NrOb2}$ (SHP), Gck, and to lesser extent Gls2 (Fig. 4j). These results suggest that reduced LRH-1-dependent glucose and glutamine metabolism could contribute to the inhibition of cytokine production in LPS-stimulated macrophages.

\section{LRH-1 inhibition impairs the LPS-dependent increase in glycolysis and glutaminolysis resulting in reduced macrophage cytokine production}

Regulation of glutamine, glucose, and fatty acids metabolic pathways is essential for energy production and macromolecule biosynthesis, also in macrophages ${ }^{23}$. Interestingly, depending on environmental conditions and stimuli, macrophages are able to reprogram their metabolic pathways in order to cope with different requirements and functions, for example, pro- or antiinflammatory activities. For example, hallmarks of LPSactivated macrophages are enhanced glycolysis, increased pentose-phosphate pathway, and fatty acid synthesis, as well as impaired mitochondrial oxidative phosphorylation and reduced TCA (tricarboxylic acid) cycle with the accumulation of citrate and succinate ${ }^{23}$. This effect, known as aerobic glycolysis or the Warburg effect ${ }^{24}$, allows these macrophages to support their demand for energy and specific metabolites, in order to sustain their high secretory and phagocytic function ${ }^{25}$. Accordingly, 


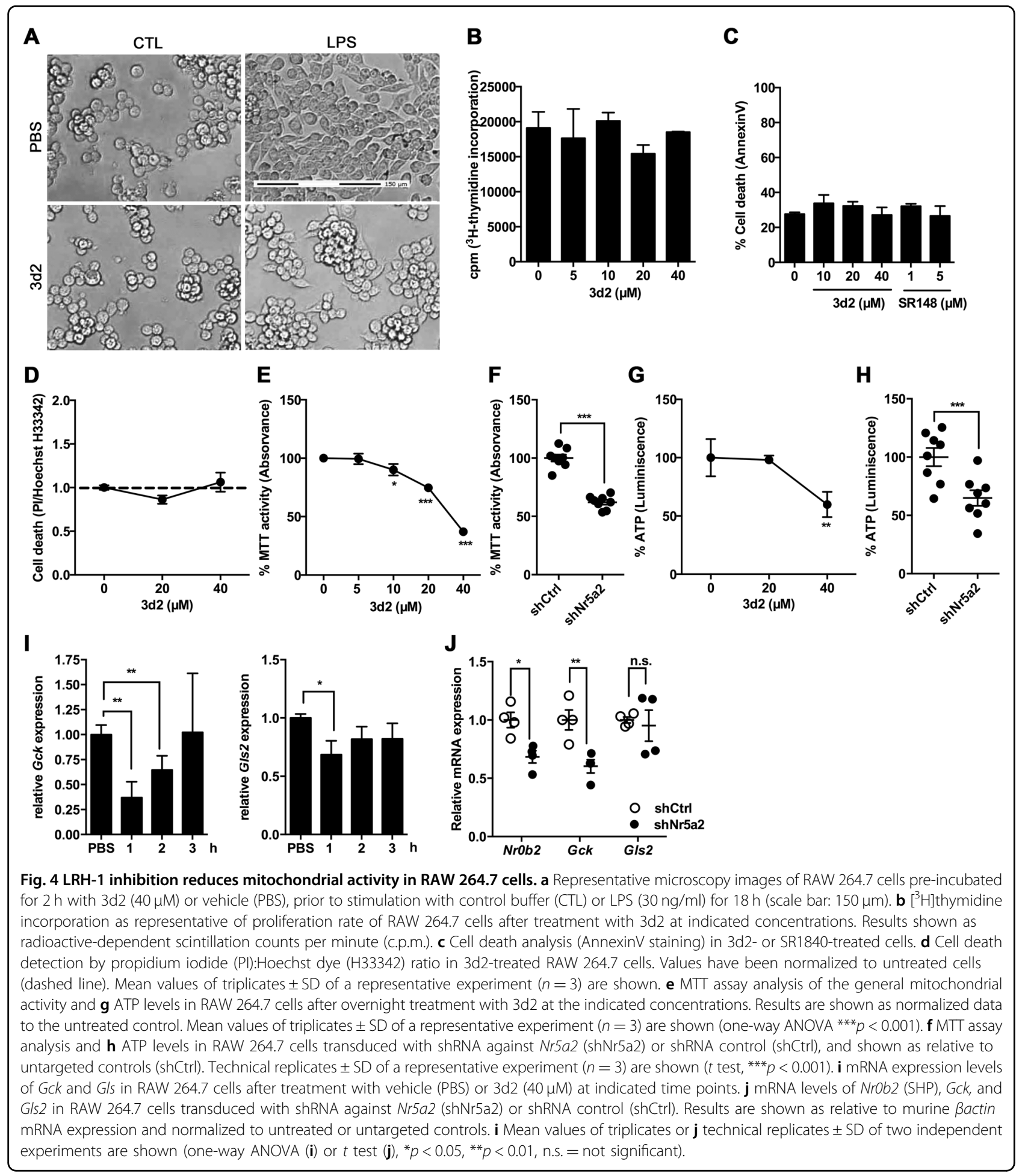

LPS stimulation of RAW 264.7 cells resulted into increased levels of lactate production, indicating enhanced glycolysis. Interestingly, this effect was reduced when LRH-1 was inhibited by $3 \mathrm{~d} 2$ (Fig. $5 \mathrm{a}$ ). Thus, it seems feasible that the 3d2-mediated downregulation of the LRH-1 targets Gck and Gls2 might contribute to the reduced glycolysis and glutaminolysis in LPS-activated macrophages, resulting in impaired macrophage activation and cytokine production.

In order to confirm this hypothesis, we investigated whether supplementation of the culture medium with either pyruvate (Pyr) or L-glutamine (Gln) could restore 

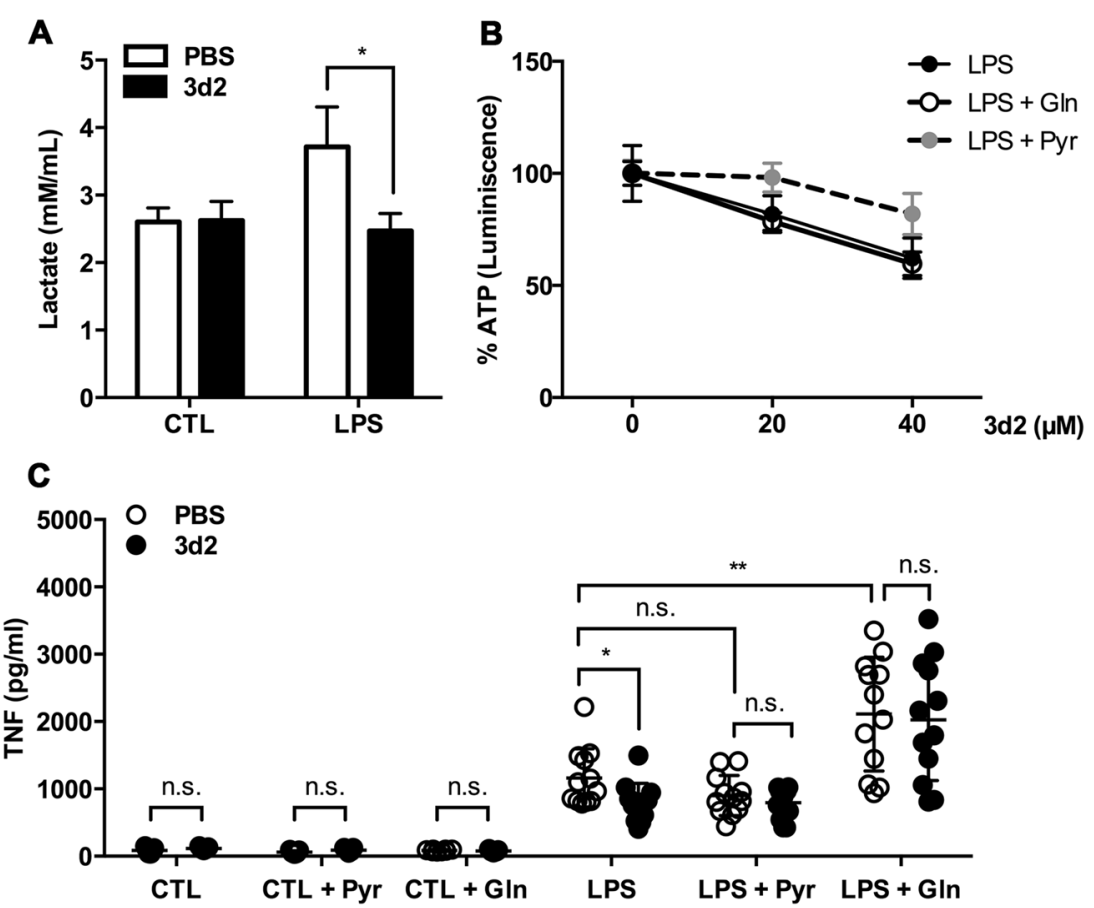

Fig. $\mathbf{5}$ LRH-1 inhibition limits glycolysis and glutaminolysis in RAW $\mathbf{2 6 4 . 7}$ cells. a Lactate produced in RAW 264.7 cells supernatant after $2 \mathrm{~h}$ pretreatment with $3 \mathrm{~d} 2(40 \mu \mathrm{M})$ or control buffer (PBS), and subsequently stimulated with control buffer (CTL) or LPS (30 ng/ml) for $18 \mathrm{~h}$. Mean values of triplicates \pm SD of a representative experiment $(n=2)$ are shown $\left(t\right.$ test; $\left.{ }^{*} p<0.05\right)$. b ATP levels of RAW 264.7 cells after pre-treatment for $2 \mathrm{~h}$ with control buffer $(C T L)$ or $3 \mathrm{~d} 2$ at indicated concentrations in the medium at normal conditions, or medium supplemented with $8 \mathrm{mM}$ pyruvate (Pyr) or $4 \mathrm{mM}$ L-glutamine $(\mathrm{Gln})$, following $18 \mathrm{~h}$ stimulation with LPS $(30 \mathrm{ng} / \mathrm{ml})$. The percentage of ATP was normalized to the untreated control. Mean values of triplicates \pm SD of a representative experiment $(n=3)$ are shown. c TNF levels in the supernatant of RAW 264.7 cells pre-treated for $2 \mathrm{~h}$ with vehicle (PBS) or $3 \mathrm{~d} 2(40 \mu \mathrm{M})$, following $18 \mathrm{~h}$ stimulation with control buffer $(\mathrm{CTL})$ or LPS $(30 \mathrm{ng} / \mathrm{ml})$ in normal culture medium, or medium supplemented with $8 \mathrm{mM}$ pyruvate (Pyr) or $4 \mathrm{mM}$ Gln. Pooled values (three to four technical replicates) of three independent experiments \pm SD are shown ( $t$ test or two-way ANOVA; ${ }^{*} p<0.05,{ }^{* *} p<0.01$, n.s. $=$ not significant).

cellular ATP levels and LPS-induced cytokine production. Remarkably, only Pyr, but not Gln, supplementation was able to restore the reduced ATP levels upon $3 \mathrm{~d} 2$ treatment (Fig. 5b). However, either Gln or Pyr supplementation could reverse the 3d2-mediated inhibition of LPS-induced TNF production in RAW 264.7 cells (Fig. 5c). These results indicate that pharmacological inhibition of LRH-1 indeed impacts cellular glycolysis and glutaminolysis in macrophages, which impairs LPSinduced cytokine production. However, as Gln supplementation was not only able to neutralize the $3 \mathrm{~d} 2$ mediated inhibition on LPS-induced TNF production, but to even further increase it, Gln-dependent anaplerosis seems to be more critical in the regulation of macrophage effector functions than intracellular Pyr or ATP levels.

Stimulation of TLR4 by LPS results in the rapid activation of mitogen-activated protein (MAP) kinase and nuclear factor- $\mathrm{kB}(\mathrm{NF \kappa B})$, and the transcriptional regulation of the pro-inflammatory TNF, IL-6, and IL- $1 \beta^{26}$. Also, LPS stimulation of BMDMs promoted the phosphorylation and activation of the MAP kinases ERK1/2 (extracellular signal-regulated kinase 1/2) and p38, as well as the activation of NF- $\mathrm{kB}$, as illustrated by the degrada-

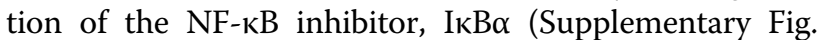
$2 \mathrm{~A})$. In line with the relevance of these pathways, a significant reduction of TNF production was observed in LPS-stimulated macrophages upon treatment with the MAP kinase inhibitor U0126, along with a strong inhibition of ERK activation and a partial inhibition of p38 (Supplementary Fig. 2A, B). Similarly, also macrophage pre-treatment with $3 \mathrm{~d} 2$ resulted in reduced MAP kinase

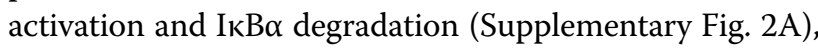
although to a lower degree than U016, which correlated well with the inhibition of LPS-induced TNF production by these two inhibitors (Supplementary Fig. 2B).

\section{3d2-mediated LRH-1 inhibition protects from TNF- dependent hepatitis}

Given the important role of TNF in the pathogenesis of various immunopathological disorders ${ }^{27}$, we next aimed to investigate whether inhibition of LRH-1 could be used to pharmacologically target macrophage-mediated, TNFdependent tissue destruction. Simultaneous intraperitoneal (i.p.) injection of LPS and the hepatic transcriptional 
inhibitor GalN in wild-type C57BL/6 mice leads to massive LPS-induced TNF production by liver LPS-activated macrophages and GalN-mediated sensitization of hepatocyte to TNF-induced apoptosis, resulting in massive liver damage and associated hepatitis ${ }^{28}$. Indeed, LPS/GalN injection caused a remarkable increase in serum TNF (Fig. 6a), serum transaminase (alanine aminotransferase (ALT)) (Fig. 6b), and hepatocyte apoptosis (Fig. 6c). Excitingly, treatment of mice with $3 \mathrm{~d} 2$ not only reduced LPS-induced TNF levels but also significantly lowered liver damage as documented by lower serum ALT and reduced cleaved caspase-3-positive hepatocytes (Fig. 6a-c). Of interest, even though hepatocytes express high levels of LRH-1 (Fig. 1a), treatment of mice with $3 \mathrm{~d} 2$ alone caused only a moderate increase in serum transaminases (Fig. 6b) and no hepatocyte apoptosis could be observed. Our results indicate that pharmacological inhibition of LRH-1 using indicated $3 \mathrm{~d} 2$ concentrations is relatively well tolerated by the liver, and opens a window of opportunity to target LRH-1 pharmacologically during inflammatory disorders with a major macrophage contribution.

In summary, we here show that LRH-1 is expressed in macrophages, and critically contributes to LPS-induced expression and secretion of pro-inflammatory cytokines. We provide further evidence that pharmacological targeting of LRH-1 results in reduced TNF-dependent hepatitis. Finally, this study supports the notion that LRH-1 has important, so far underestimated function in the regulation of the immune system ${ }^{12,13}$.

\section{Discussion}

The important role of LRH-1 in physiological as well as pathophysiological processes in endodermal tissues is well established, and thus the development of drugs able to manipulate LRH-1 activities is under extensive research. For example, the role of LRH-1 in the regulation of lipid and glucose metabolism in the liver is subject to experimental targeting during metabolic syndrome and in type 1 and 2 diabetes ${ }^{2-6,21,29}$. Similarly, LRH-1 is overexpressed in many tumors of endodermal tissues, such as hepatocellular carcinoma, pancreatic tumors, and colorectal cancers, where it drives proliferation via the transcriptional control of cell cycle-regulating genes, such as cyclins D1 and $\mathrm{E} 1^{7,10,30-32}$. Thus, LRH-1 inhibitors may have great potential in the treatment of these tumors ${ }^{33}$. In this regards, 3d2 and SR1848 have been shown to represent interesting lead compounds, which rather selectively inhibit LRH-1, although by different mechanisms and with different potencies ${ }^{12,15,16}$.

As reported by our group and others, increasing evidence revealed that LRH-1 is not only present in endodermal tissues and tumors but it is also expressed at lower levels in immune cells (see Fig. 1 and refs. ${ }^{10-13}$ ). Substantially lower expression levels do, however, not necessarily mean that LRH-1 is less relevant in immune cells. Of interest, although LRH-1 is strongly expressed in the liver and intestine, where it fulfills important functions, deletion of LRH-1 in these tissues still results in functional liver, resp. intestine, even though certain
A

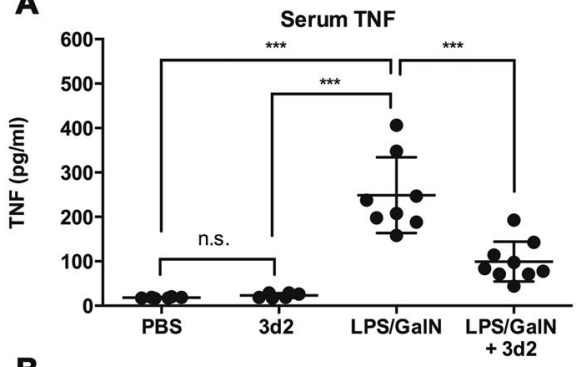

B

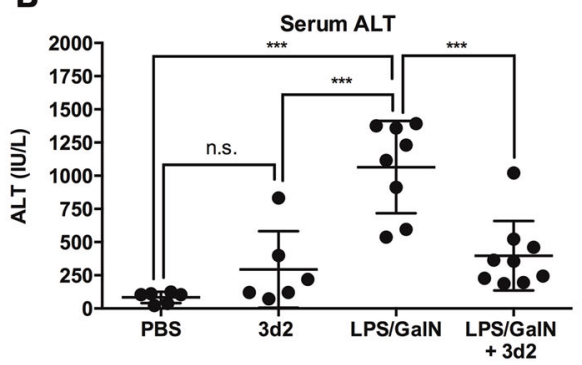

C

CTL

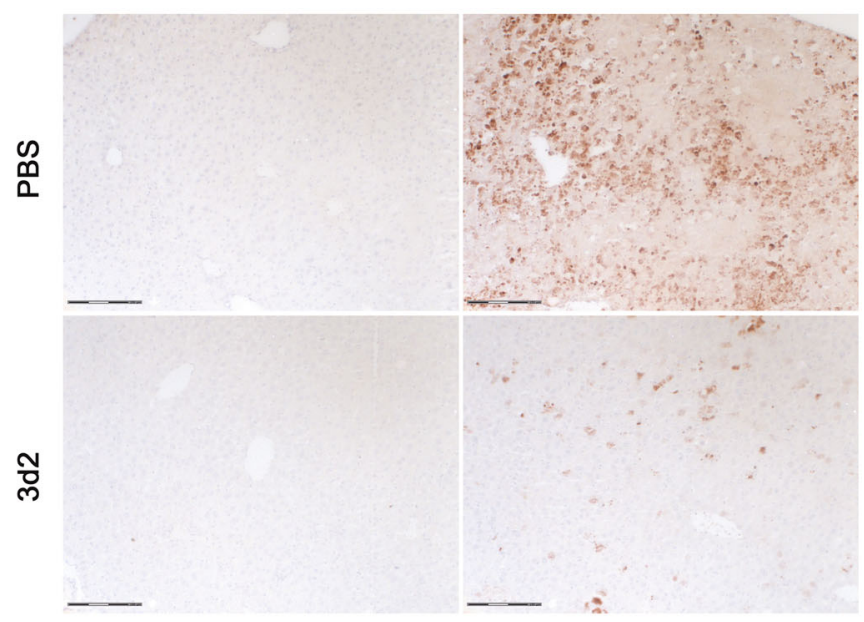

Fig. 6 LRH-1 inhibition protects from TNF-dependent hepatitis. Wild-type C57BL/6 mice ( $n=6-9$ per group) were pre-treated with vehicle (PBS) or $3 \mathrm{~d} 2$ (50 mg/kg body weight) i.p. injections for $1 \mathrm{~h}$ and then challenged by i.p. injections of LPS (0.2 mg) and GalN (40 mg). Serum was harvested for the analysis of $\mathbf{a}$ TNF protein concentrations and $\mathbf{b}$ transaminase (ALT) levels ( $t$ test; ${ }^{* * *} p<0.001$, n.s. $=$ not significant). $\mathbf{c}$ Immunohistochemical detection of cleaved caspase-3-positive, apoptotic hepatocytes in liver sections from untreated (CTL) or LPS/GalN i.p. injected mice pre-treated with PBS or $3 \mathrm{~d} 2$ as described above (scale bar: $150 \mu \mathrm{m})$. 
processes are diminished or altered ${ }^{5,8,21,34}$. In marked contrast, we recently demonstrated that the deletion of LRH-1 in T cells, although only expressed at very low levels, results in a drastic reduction in absolute $\mathrm{T}$ cell numbers, and particularly, in the inability to mount protective immune responses or immunopathologies ${ }^{13}$. This stronger LRH-1 dependency of immune cells compared to endodermal tissue offers an interesting window of opportunity. Thus, while systemic deletion of LRH-1 is lethal $^{35}$, the transient use of LRH-1 inhibitors could be helpful to treat acute episodes of inflammation and immunopathologies, yet leaving LRH-1-positive tissue cells mostly unaffected. It is interesting to point out that acute treatment of mice with the LRH-1 inhibitor $3 \mathrm{~d} 2 \mathrm{did}$ not cause any significant liver damage, yet was able to reduce macrophage-induced and TNF-mediated acute hepatitis (Fig. 6). Similarly, we have previously shown that $3 \mathrm{~d} 2$ can inhibit FasL expression in $\mathrm{T}$ cells and thereby reduce $\mathrm{T}$ cell-mediated liver damage and hepatitis ${ }^{12}$. These findings illustrate the great potential of LRH-1 inhibitors in the treatment of immune cell-mediated pathologies.

In this study, we not only show that LRH-1 has important function in macrophages in the regulation of LPS-induced cytokine expression, but also we show that LRH-1 is druggable in vitro and in vivo, leading to reduced expression and release of pro-inflammatory cytokines and associated immunopathologies. It partly confirms in part a recent publication by Lefrevre and colleagues ${ }^{11}$ demonstrating an important role for LRH-1 in IL-13-induced macrophage polarization and effector functions. Even though this report rather suggested an anti-inflammatory role of LRH-1 in M2 macrophages, our study on LPS-induced expression of pro-inflammatory cytokines points out that LRH-1 may also have an important role in the activation of M1 macrophages. It therefore seems that the role of LRH-1 in the regulation of differentiation, polarization, and macrophage effector functions is much broader than initially thought. Clearly, more detailed studies will be required to understand the relative role of LRH-1 in various aspects of macrophage biology.

How does LRH-1 inhibition affect the LPS-induced expression of pro-inflammatory cytokines? A reasonable first guess would be that as a transcription factor LRH-1 directly regulates the expression of TNF, IL-6, and IL- $1 \beta$. We have previously shown that FasL, a close homolog of TNF, is a direct transcriptional target of LRH- ${ }^{12}$. Yet so far, we failed to identify obvious LRH-1-binding sites in the Tnf, Il6, and $I l 1 b$ promoters. Thus, LRH-1 appears to regulate macrophage functions in a more general manner and upstream of the transcription of these cytokines. An interesting hint comes from the observation that pharmacological inhibition of LRH-1 prevents the LPS- induced morphology of activated macrophages (Fig. 4). Similarly, we have seen that the general mitochondrial activity (MTT), as well as the ATP concentration, is drastically reduced in 3d2-treated cells. Indeed, loss of LRH-1 has been very recently related to reduced mitochondrial function and ATP production in hepatocytes ${ }^{22}$. Thus, it is very likely that LRH-1 inhibition results in reduced or altered metabolism in LPS-stimulated macrophages, which impairs downstream effector functions, such as the secretion of pro-inflammatory cytokines. In line with this notion, we have seen that the expression of established LRH-1 target genes Gck and Gls2 (Fig. 4) were reduced upon treatment with $3 \mathrm{~d} 2$. Furthermore, culture medium supplementation with Pyr or Gln was able to restore 3d2-mediated inhibition of LPS-induced TNF production (Fig. 5). As the addition of Gln had a general enhancing effect on LPS-induced TNF expression, it is likely that LRH-1-regulated mitochondrial anaplerosis is more critical for these processes than cellular ATP levels, as being restored by Pyr (Fig. 5). In this regard, when glycolytic rates are reduced, as observed in $3 \mathrm{~d} 2$-treated macrophages, alternative metabolites can fuel the TCA cycle in order to cope with the LPS-induced metabolic requirements ${ }^{36}$.

Although changes in energy metabolism have a great impact on vital functions of cells, such as proliferation and death/survival, we were able to exclude impaired proliferation or cytotoxicity as one of the underlying reasons for reduced expression of pro-inflammatory cytokines in 3d2-treated macrophages (Fig. 4). Thus, it is likely that other pathways or processes must be involved. Given the importance of MAP kinase pathways and NF- $\mathrm{kB}$ activation in the LPS-induced expression of pro-inflammatory cytokines $^{26}$, and the reduced activation of these signaling processes in 3d2-treated macrophages (Supplementary Fig. 2), it is very likely that LRH-1-regulated metabolic processes, including but not restricted to Gls2 and Gck regulation, are involved in the fine-tuning of these signaling cascades. Yet, how these processes are linked is incompletely understood. LPS-induced macrophage polarization has been shown to highly relay on Pyr dehydrogenase activity, suggesting a higher demand for glucose-dependent Pyr production. In this regard, Meiser et al. ${ }^{23}$ were able to inhibit LPS-dependent TNF production by using a specific Pyr transporter inhibitor (UK5099). Similarly, in LPS-stimulated macrophages Gln is consumed at high rate and enters the TCA cycle through glutaminolysis, mostly contributing to succinate accumulation ${ }^{37}$. Interestingly, inhibitors affecting succinate levels in LPS-stimulated macrophages greatly impact the stabilization and activation of the hypoxia-inducible factor- $1 \alpha^{25,38}$, and thereby the induction of its transcriptional target IL- $1 \beta$, while TNF remains unaffected ${ }^{37}$. This result suggests specific metabolite requirements for the 
proper cytokine production in LPS-stimulated macrophages. Of note, glycolysis inhibition with 2-deoxyglucose, a glucose derivative unable to undergo glycolysis, also results in reduced succinate levels and LPS-induced IL-1 $\beta$ expression, suggesting that both glycolysis and glutaminolysis contribute to the regulation of effector functions in LPS-stimulated macrophages ${ }^{37,39}$. As these effects are, however, restricted to LPS-induced IL$1 \beta$ expression, they cannot explain the effect of LRH-1 inhibition on TNF and IL-6 expression. Thus, alternative LRH-1-regulated pathways must exist in macrophages and remain to be identified.

In summary, our study demonstrates a novel role for LRH-1 in the regulation of LPS-induced cytokine expression in macrophages. Furthermore, the successful inhibition of TNF-mediated hepatitis proposes LRH-1 inhibition as a novel therapeutic approach in the treatment of acute inflammatory disorder.

\section{Materials and methods Reagents}

The LRH-1 inhibitor $3 \mathrm{~d} 2$ was re-synthesized according to the publication of Benod et al. ${ }^{15}$ at ChemBridge Corp (San Diego, CA, USA). The LRH-1 inhibitor SR1848 was obtained from Sigma-Aldrich (Steinheim, Germany) and the MAPK kinase (MEK) inhibitor U0126 from New England Biolab (Ipswich, MA, USA). Gln and LPS was from Salmonella minesota strains and GalN were purchased from Sigma-Aldrich (Steinheim, Germany).

\section{Mice}

Male and females wild-type C57BL/6 mice and SHP $-/-$ mice were used between 10 and 12 weeks for ex vivo and in vivo experiments. Mice were bred and kept in the animal facility of the University of Konstanz. All animal experiments complied with animal experimentation regulations of Germany and were approved by the Ethics Review Committee of the regional council.

\section{Cell culture}

RAW 264.7 cells, a SV40 virus-transformed peritoneal macrophage cell line from a male BALB/c mouse, was obtained from ATCC and maintained in Dulbecco's modified Eagle's mMedium (DMEM) medium (Sigma). All cell culture media were supplemented with $10 \%$ fetal calf serum (Sigma) and $50 \mu \mathrm{g} / \mathrm{ml}$ gentamicin (Sigma), and in some experiments, the medium was supplemented with $4 \mathrm{mM}$ Gln or $8 \mathrm{mM}$ Pyr.

\section{Culture and differentiation of human PBMC-derived monocytes}

Blood from healthy donors was collected on the same day as the assays were performed. The blood was diluted 1:1 with phosphate-buffered saline (PBS). Afterwards, diluted blood was layered on the top of a Ficoll-Hypaque solution (HISTOPAQUE -1077 , Sigma) and PBMCs were isolated after density gradient centrifugation. The cells were washed twice with Hank's balanced salt solution (Sigma) $2 \times 10^{6}$ cells were seeded into $75-\mathrm{cm}^{2}$ flasks. Monocyte enrichment was performed by adherence for $1 \mathrm{~h}$ at $37^{\circ} \mathrm{C}$ in a humidified incubator $5 \% \mathrm{CO}_{2}$. Nonadherent cells were removed by washing the flasks twice with RPMI.

\section{Culture and differentiation of BMDMs}

C57BL/6 wild-type and SHP-/- mice were sacrificed for the isolation of marrow cells from femur and tibia bones. The bones were cut at both ends open and flushed with DMEM medium. Bone marrow cells were passed through a cell strainer and washed with DMEM medium in order to generate single-cell suspension. Cell numbers were adjusted to $2 \times 10^{6}$ cells $/ \mathrm{ml}$ and plated in $10-\mathrm{cm}$ culture dishes for macrophage differentiation. Bone marrow macrophage progenitors were differentiated in complete DMEM medium containing 10\% L929conditioned medium for 7 days. In between, cells were washed twice with PBS every 2 days and fresh medium was added afterwards. After 7 days, fully differentiated macrophages were washed with PBS and nonmacrophages were removed by incubation with $0.25 \%$ trypsin/EDTA for $5 \mathrm{~min}$. Macrophages were harvested by incubation with fresh $0.25 \%$ trypsin/EDTA for $20 \mathrm{~min}$ and seeded for further experiments. Fully differentiated cells were seeded into 96 -well plates $(60,000$ cells/well). After overnight adherence, cells were treated with respective inhibitors and stimulated with LPS.

\section{Isolation of Kupffer cells}

Kupffer cells were enzymatically dissociated from murine liver samples using a two-step enzymatic microperfusion technique with collagenase, as described previously ${ }^{40}$. Kupffer cells were cultured in DMEM containing $10 \%$ FCS, $4 \mathrm{mM}$ Gln, and $30 \mu \mathrm{g} / \mathrm{ml}$ gentamicin at $37^{\circ} \mathrm{C}$ and $5 \% \mathrm{CO}_{2}$.

\section{Transfection/transduction}

RAW 264.7 cells were passaged $24 \mathrm{~h}$ prior to transfection at a ratio of 1:3. A total of $2.0 \times 10^{6}$ cells were transfected with $6 \mu \mathrm{g}$ of plasmid DNA in a Gene Pulser Cuvette (Bio-Rad) by electroporation using an Amaxa Nucleofector Device (Lonza). Electroporated cells were pooled in complete medium and seeded into a tissue culture dish for further experiments.

LRH-1 downregulation in RAW 264.7 cells was performed using lentiviral expression vectors containing shRNA sequence against murine LRH-1 (shNr5a2, clone ID: NM_030676.1-1160s1c1, Sigma-Aldrich) or corresponding untargeted control. Cells were selected with 
puromycin (Sigma-Aldrich) for at least 2 days prior to experiments.

\section{Reporter assays}

RAW 264.7 cells were transiently transfected with expression and luciferase reporter plasmids. The LRH-1 reporter containing five copies of the LRH-1 response element has been described previously ${ }^{14}$ (Promega). Cotransfection of $\beta$-galactosidase expression plasmid (Invitrogen) served for normalization. One day after transfection, cells were either control treated or treated with different concentrations of the LRH-1 inhibitors for $18 \mathrm{~h}$. Cells were then lysed, and luciferase and $\beta$-galactosidase activity was measured in cell lysates as described previously ${ }^{41}$.

\section{RNA isolation and quantitative PCR}

For RNA isolation, cells were lysed in $1 \mathrm{ml}$ peqGOLD TriFast reagent (PeqLab) and RNA was isolated according to the manufacturer's protocol. One microgram of RNA was reverse transcribed using a High-Capacity cDNA Reverse Transcription Kit (Applied Biosystems) and cDNAs (complementary DNAs) were used for quantification of gene expression by quantitative real-time PCR using FAST SYBR Green Master Kit System. Murine Nr5a2 and corresponding $A c t b$ transcripts were detected using a FAM-based TaqMan probe and the Volcano3G RT-PCR Probe Master Mix (myPols Biotec $\mathrm{GmbH}$ ). All of them were quantified by using a StepOnePlus Real-time PCR System (Applied Biosystems). All gene-specific primers were designed to span an exon-exon junction to detect specific mRNA transcripts. Gene expression was normalized using murine $\beta$ Actin or murine Gapdh. The following primers were used: murine BActin: 5'-TATTGGCAACGAGCGGTTCC-3' (forward), 5'-GCACTGTGTTGGCATAGAGG-3' (reverse); murine Gapdh: 5'-CGTCCCGTAGACAAAATGGT-3' (forward), $5^{\prime}$-TCTCCATGGTGGTGAAGACA-3' (reverse); murine Il1 $b$ : 5'-TGCCACCTTTTGACAGTGATG-3' (forward), 5'-AT GTGCTGCTGCGAGATTTG-3' (reverse); murine Il6: 5'-C ACAAGTCCGGAGAGGAGAC-3' (forward), 5'-TTGCCA TTGCACAACTCTTT-3' (reverse); murine Tnf. 5' -TAGCC CACGTCGTAGCAAAC-3' (forward), 5'-ACAAGGTACA ACCCATCGGC-3' (reverse); murine $\mathrm{NrOb2}$ from Quantitec primers, GeneGlobe, Qiagen (NM_011850, \# 249900); murine Gck: ACATTGTGCGCCGTGCCTGTGAA (forward), A GCCTGCGCACACTGGCGTGAAA (reverse); murine Gls 2: GACCGTGGTGAACCTGCTAT (forward), TGCGGGA ATCATAGTCCTTC (reverse). murine Nr5a2: CGCATGG GAAGGAAGGGACAATCT (probe), GCTGGAGTGAGC TCTTGATT (forward), GTGTGAGATGATGGTGGAGT AG (reverse); murine Actinb: probe TGGCATTGTTACC AACTGGGACGA (probe), GAGGTATCCTGACCCTGAA GTA (forward), CACACGCAGCTCATTGTAGA (reverse).

\section{Enzyme-linked immunosorbent assay (ELISA)}

Cells were pre-treated with LRH-1 inhibitors for $2 \mathrm{~h}$ and then were stimulated with LPS for $18 \mathrm{~h}$. Plates were centrifuged and supernatant was collected. The following cytokines were detected by using ELISA-based matched antibody pairs (BioLegend); murine TNF (clone TN319.12, \# 506102, $3 \mu \mathrm{g} / \mathrm{ml}$, BioLegend and clone Poly5160, \# 516003, $1 \mu \mathrm{g} / \mathrm{ml}$, BioLegend) or human TNF (clone MAb1, \# 502802, $1 \mu \mathrm{g} / \mathrm{ml}$, BioLegend and clone Mab11, BioLegend \# 502904, $0.5 \mu \mathrm{g} / \mathrm{ml}$ ), IL-6 (clone MP5-20F3, \# $504502,1 \mu \mathrm{g} / \mathrm{ml}$, BioLegend and clone MP5-32C1, \# $504602,1 \mu \mathrm{g} / \mathrm{ml}$, BioLegend). IL-1 $\beta$ was analyzed with the DuoSet ELISA Development Kit Mouse IL-1 $\beta$ (R\&D Systems, \# DY401-05) according to the manufacturer's instructions. For the detection of the secondary antibodies, streptavidin conjugated to horseradish peroxidase (Calbiochem, \# 189733) and TMB substrate (BioLegend \# 421101) were used following the manufacturer's instruction. The reaction was stopped by the addition of $1 \mathrm{M}$ $\mathrm{H}_{2} \mathrm{SO}_{4}$ and cytokine concentration was quantified by measuring the absorbance at a wavelength of $450 \mathrm{~nm}$ (reference wavelength $570 \mathrm{~nm}$ ) with a microplate absorbance reader (Sunrise Tecan Reader).

\section{MTT respiration assay and ATP measurement}

MTT (Sigma-Aldrich) solution was added to the RAW 264.7 cell culture to a final concentration of $500 \mu \mathrm{g} / \mathrm{ml}$ and incubated for $1-2 \mathrm{~h}\left(37^{\circ} \mathrm{C}, 5 \% \mathrm{CO}_{2}\right)$. After discarding the medium, MTT was solubilized in $100 \mu \mathrm{l}$ of dimethyl sulfoxide (DMSO) (Roth) per well (15 min, room temperature) and the absorbance was measured on a microplate absorbance reader (Sunrise Tecan Reader) at $562 \mathrm{~nm}$. The decrease in cell respiration (\%) was calculated as $100 \times(1-(\mathrm{OD}$ exp. mean value (- substrate blank)/OD control mean value (- substrate blank)). Cellular ATP measurements were performed using the CellTiter-Glo 2.0 Kit (Promega) according to the manufacturer's instructions.

\section{Lactate measurement}

Lactate concentrations in RAW 264.7 cell supernatants were determined by using LAC 142 lactate test (Diaglobal $\mathrm{GmbH}$ ), according to the manufacturer's instructions. LPS-treated controls were used as a reference.

\section{Western blot analysis}

BMDMs were treated for $2 \mathrm{~h}$ with control buffer (UT), 3d2 $(40 \mu \mathrm{M})$, or the MEK inhibitor U0126 (10 $\mu$ M; SigmaAldrich) and then stimulated with $100 \mathrm{ng} / \mathrm{ml} \mathrm{LPS} \mathrm{for}$ $60 \mathrm{~min}$. Cells were then lysed in NP-40 lysis buffer (150 mM NaCl, $50 \mathrm{mM}$ Tris, $\mathrm{pH}$ 7.6, $1 \mathrm{mM}$ EDTA, and 1\% NP-40) and lysates were separated on a denaturing $12 \%$ sodium dodecyl sulfate-polyacrylamide gel electrophoresis 
gel. After transfer to polyvinylidene difluoride membranes (Roche), membranes were incubated overnight at $4{ }^{\circ} \mathrm{C}$ with antibodies against phospho-specific ERK1/2 (\# 9101), phospho-p38 (\# 4511), c-Jun N-terminal kinase (\# 9252), and IкB $\alpha$ (\# 9242) antibodies (1:1000; Cell Signaling Technology) or mouse anti-tubulin (\# T5168, 1:4000; Sigma-Aldrich) as a loading control.

\section{Detection of cell death by AnnexinV staining}

Cells were exposed to $3 \mathrm{~d} 2(0-40 \mu \mathrm{M})$ or SR148 $(0-5 \mu \mathrm{M})$ overnight, harvested, and resuspended in AnnexinV binding buffer (10 mM HEPES, $150 \mathrm{mM} \mathrm{NaCl}$, $5 \mathrm{mM} \mathrm{KCl}, 1 \mathrm{mM} \mathrm{MgCl}_{2}, 1.8 \mathrm{mM} \mathrm{CaCl}_{2}$ ) containing $1 \mu \mathrm{g} /$ $\mathrm{ml}$ fluorescein isothiocyanate-labeled AnnexinV. Cell suspensions were analyzed on a LS Fortessa cytometer (BD Biosciences). A total of 10,000 cells were analyzed for each sample. The percentage of AnnexinV-positive apoptotic cells with respect to total cells was determined using the FlowJo software (version 10).

\section{Detection of cell death by $\mathrm{PI} / \mathrm{Hoechst}$ dye staining}

Cells cultured in phenol-red free medium were exposed to $3 \mathrm{~d} 2(0-40 \mu \mathrm{M})$ overnight, and then stained with PI and Hoechst $\mathrm{H} 33342$ at a final concentration of $1 \mu \mathrm{g} / \mathrm{ml}$ each. Staining solution (dyes in PBS) was directly added to the culture medium. Cells were stained for $30 \mathrm{~min}$ at $37^{\circ} \mathrm{C}$, $5 \% \mathrm{CO}_{2}$ for subsequent analysis. Top-well measurements were performed in a microplate fluorescence reader (Sunrise Tecan Reader), where excitation and emission wavelengths for PI were 535 and $617 \mathrm{~nm}$ and for H33342, 361 and $486 \mathrm{~nm}$, respectively, as described previously ${ }^{20}$.

\section{$\left[{ }^{3} \mathrm{H}\right]$ thymidine incorporation assay}

At $24 \mathrm{~h}$ prior to the treatment, $2 \times 10^{4}$ cells per well were seeded into a 96-well plate. After $6 \mathrm{~h}$ with $3 \mathrm{~d} 2$ treatment, cells were labeled with $0.5 \mu \mathrm{Ci}$ [methyl ${ }^{3} \mathrm{H}$ ] thymidine (Hartmann Analytic) per well for $18 \mathrm{~h}$ in a humidified incubator with $5 \% \mathrm{CO}_{2}$ at $37^{\circ} \mathrm{C}$. Afterwards, ${ }^{3} \mathrm{H}$-thymidine-labeled DNA was harvested onto glass fiber filters using Omnifilter-96 cell harvester (PerkinElmer). The amount of radioactivity incorporated into DNA and proportional to the amount of proliferating cells was measured using a Top Count Microplate Scintillation Counter (PerkinElmer). The readout was expressed as counts per minute (c.p.m.) per well.

\section{LPS/GalN-induced hepatitis}

LPS and GalN were diluted in sterile endotoxin-free PBS. Wild-type C57BL/6 male mice were pre-treated with $3 \mathrm{~d} 2$ ( $50 \mathrm{mg} / \mathrm{kg}$ body weight, dissolved in 10\% DMSO in PBS) by i.p. injection $1 \mathrm{~h}$ before the LPS/GalN i.p. injection (100 ng/ $\mathrm{ml}, 20 \mathrm{mg} / \mathrm{ml}$ in $200 \mu \mathrm{l})$. Six hours after the challenge, mice were sacrificed and serum samples were collected. Liver samples were fixed in formalin, dehydrated, and paraffin embedded for histological analysis or cleaved caspase-3 immunohistochemistry.

\section{Transaminase assay}

For quantitative determination of ALT activity in the serum of mice, an ALT Reagent Colorimetric Endpoint Method Kit (Teco Diagnostics) was used according to the manufacturer's recommendation with 1:5 diluted sera.

\section{Histology and immunohistochemistry}

Formalin-fixed and paraffin-embedded liver tissues sections were counter-stained with hematoxylin and eosin staining for histological analysis. Apoptotic cells in tissue sections were detected using an anti-cleaved caspase-3 antibody (Clone Asp175, Cell Signaling Technology), as described previously ${ }^{42}$. All sections were observed and photographed with the PALM MicroBeam microscope (Zeiss).

\section{Statistical analysis}

Student's unpaired $t$ test and ordinary one-way analysis of variance (ANOVA) or two-way ANOVA were performed using the Prism7 software (GraphPad Software) to identify significant differences between experimental groups. Bonferroni was the multiple comparison test used when needed. A $p$ value of $>0.05,<0.05,<0.01$, and $<0.001$ was regarded significant and marked as n.s., *, **, and ${ }^{* * * *}$, respectively.

\section{Acknowledgements}

We thank Cindy Reinhold, Franziska Hartung, and Josefine Negrassus for expert technical help, and Kristina Schoonjans for the LRH-1 luciferase reporter constructs and the SHP-deficient mice. This work was supported by grants from the German Science Foundation (BR 3369/4-1, INST 38/500-1, INST 38/ 498-1) to T.B. and by an INNOSYSTOX (BMBF) grant to M.L. J.D. was supported by a Research and Art-funded Co-operative research training school

"Advanced in vitro test systems for the analysis of cell-chemical interactions in drug discovery and environmental safety" (InViTe) fellowship from BadenWürttemberg Ministry of Science and MED by an Independent Research Grant from the Zukunftskolleg of the University of Konstanz.

\section{Author details}

${ }^{1}$ Biochemical Pharmacology, Department of Biology, University of Konstanz, Konstanz, Germany. ${ }^{2}$ In Vitro Toxicology and Biomedicine, inaugurated by the Doerenkamp-Zbinden Foundation, Department of Biology, University of Konstanz, Konstanz, Germany. ${ }^{3}$ Cooperative Doctorate College InViTe, University of Konstanz, Konstanz, Germany

\section{Conflict of interest}

The authors declare that they have no conflict of interest.

\section{Publisher's note}

Springer Nature remains neutral with regard to jurisdictional claims in published maps and institutional affiliations.

Supplementary Information accompanies this paper at (https://doi.org/ 10.1038/s41419-020-2348-9).

Received: 8 August 2019 Revised: 10 February 2020 Accepted: 11 February 2020

Published online: 28 February 2020 


\section{References}

1. Stein, S. \& Schoonjans, K. Molecular basis for the regulation of the nuclear receptor LRH-1. Curr. Opin. Cell Biol. 33, 26-34 (2015).

2. $\mathrm{Xu}, \mathrm{P}$. et al. LRH-1-dependent programming of mitochondrial glutamine processing drives liver cancer. Genes Dev. 30, 1255-1260 (2016).

3. Oosterveer, M. H. et al. LRH-1-dependent glucose sensing determines intermediary metabolism in liver. J. Clin. Invest. 122, 2817-2826 (2012).

4. Matsukuma, K. E., Wang, L., Bennett, M. K. \& Osborne, T. F. A key role for orphan nuclear receptor liver receptor homologue-1 in activation of fatty acid synthase promoter by liver X receptor. J. Biol. Chem. 282, 20164-20171 (2007).

5. Lee, Y. K. et al. Liver receptor homolog-1 regulates bile acid homeostasis but is not essential for feedback regulation of bile acid synthesis. Mol. Endocrinol. 22 1345-1356 (2008)

6. Lee, J. M. et al. A nuclear-receptor-dependent phosphatidylcholine pathway with antidiabetic effects. Nature 474, 506-510 (2011).

7. Botrugno, O. A. et al. Synergy between LRH-1 and beta-catenin induces G1 cyclin-mediated cell proliferation. Mol. Cell 15, 499-509 (2004).

8. Coste, A. et al. LRH-1-mediated glucocorticoid synthesis in enterocytes protects against inflammatory bowel disease. Proc. Natl Acad. Sci. USA 104 13098-13103 (2007).

9. Mueller, M. et al. The nuclear receptor LRH-1 critically regulates extra-adrenal glucocorticoid synthesis in the intestine. J. Exp. Med. 203, 2057-2062 (2006).

10. Benod, C. et al. Nuclear receptor liver receptor homologue $1(\mathrm{LRH}-1)$ regulates pancreatic cancer cell growth and proliferation. Proc. Natl Acad. Sci. USA 108, 16927-16931 (2011)

11. Lefevre, L. et al. LRH-1 mediates anti-inflammatory and antifungal phenotype of IL-13-activated macrophages through the PPARgamma ligand synthesis. Nat. Commun. 6, 6801 (2015)

12. Schwaderer, J., Gaiser, A. K., Phan, T. S., Delgado, M. E. \& Brunner, T. Liver receptor homolog-1 (NR5a2) regulates CD95/Fas ligand transcription and associated T-cell effector functions. Cell Death Dis. 8, e2745 (2017).

13. Seitz, $\mathrm{C}$. et al. The orphan nuclear receptor $\mathrm{LRH}-1 / \mathrm{NR} 5 \mathrm{a} 2$ critically regulates $T$ cell functions. Sci. Adv. 5, eaav9732 (2019).

14. Schoonjans, K. et al. Liver receptor homolog 1 controls the expression of the scavenger receptor class B type I. EMBO Rep. 3, 1181-1187 (2002).

15. Benod, C. et al. Structure-based discovery of antagonists of nuclear receptor LRH-1. J. Biol. Chem. 288, 19830-19844 (2013).

16. Corzo, C. A. et al. Antiproliferation activity of a small molecule repressor of liver receptor homolog 1. Mol. Pharm. 87, 296-304 (2015).

17. Seol, W., Choi, H. S. \& Moore, D. D. An orphan nuclear hormone receptor that lacks a DNA binding domain and heterodimerizes with other receptors. Science 272, 1336-1339 (1996).

18. Ortlund, E. A. et al. Modulation of human nuclear receptor $\mathrm{LRH}-1$ activity by phospholipids and SHP. Nat. Struct. Mol. Biol. 12, 357-363 (2005).

19. Williams, L. M. \& Ridley, A. J. Lipopolysaccharide induces actin reorganization and tyrosine phosphorylation of Pyk2 and paxillin in monocytes and macrophages. J. Immunol. 164, 2028-2036 (2000).

20. Bode, K. J., Mueller, S., Schweinlin, M., Metzger, M. \& Brunner, T. A fast and simple fluorometric method to detect cell death in 3D intestinal organoids. Biotechniques 67, 23-28 (2019).

21. Mataki, C. et al. Compromised intestinal lipid absorption in mice with a liverspecific deficiency of liver receptor homolog 1. Mol. Cell. Biol. 27, 8330-8339 (2007).
22. Choi, S. et al. Methyl-sensing nuclear receptor liver receptor homolog-1 regulates mitochondrial function in mouse hepatocytes. Hepatology https://doi. org/10.1002/hep.30884 (2019).

23. Meiser, J. et al. Pro-inflammatory macrophages sustain pyruvate oxidation through pyruvate dehydrogenase for the synthesis of itaconate and to enable cytokine expression. J. Biol. Chem. 291, 3932-3946 (2016).

24. Warburg, O. On the origin of cancer cells. Science 123, 309-314 (1956).

25. Cramer, T. et al. HIF-1alpha is essential for myeloid cell-mediated inflammation. Cell 112, 645-657 (2003).

26. Langston, P. K., Shibata, M. \& Horng, T. Metabolism supports macrophage activation. Front. Immunol. 8, 61 (2017).

27. Delgado, M. E. \& Brunner, T. The many faces of tumor necrosis factor signaling in the intestinal epithelium. Genes Immun. https://doi.org/10.1038/s41435-0190057-0 (2019)

28. Kaufmann, T. et al. Fatal hepatitis mediated by tumor necrosis factor TNFalpha requires caspase- 8 and involves the $\mathrm{BH} 3$-only proteins Bid and Bim. Immunity 30, 56-66 (2009).

29. Cobo-Vuilleumier, $\mathrm{N}$. et al. LRH-1 agonism favours an immune-islet dialogue which protects against diabetes mellitus. Nat. Commun. 9, 1488 (2018).

30. Xiao, L. et al. LRH-1 drives hepatocellular carcinoma partially through induction of c-myc and cyclin E1, and suppression of p21. Cancer Manag. Res. 10 2389-2400 (2018)

31. Bayrer, J. R., Mukkamala, S., Sablin, E. P., Webb, P. \& Fletterick, R. J. Silencing LRH1 in colon cancer cell lines impairs proliferation and alters gene expression programs. Proc. Natl Acad. Sci. USA 112, 2467-2472 (2015).

32. Schoonjans, K. et al. Liver receptor homolog 1 contributes to intestinal tumor formation through effects on cell cycle and inflammation. Proc. Natl Acad. Sci. USA 102, 2058-2062 (2005).

33. Fletterick, R. NR5A2 discovering compounds that block tumor growth in PDAC. J. Surg. Oncol. 116, 89-93 (2017).

34. Bayrer, J. R. et al. LRH-1 mitigates intestinal inflammatory disease by maintaining epithelial homeostasis and cell survival. Nat. Commun. 9, 4055 (2018).

35. Pare, J. F. et al. The fetoprotein transcription factor (FFF) gene is essential to embryogenesis and cholesterol homeostasis and is regulated by a DR4 element. J. Biol. Chem. 279, 21206-21216 (2004)

36. Netea-Maier, R. T., Smit, J. W. A. \& Netea, M. G. Metabolic changes in tumor cells and tumor-associated macrophages: a mutual relationship. Cancer Lett 413, 102-109 (2018)

37. Tannahill, G. M. et al. Succinate is an inflammatory signal that induces IL-1beta through HIF-1alpha. Nature 496, 238-242 (2013).

38. Ren, W. et al. Glutamine metabolism in macrophages: a novel target for obesity/type 2 diabetes. Adv. Nutr. 10, 321-330 (2019).

39. Nonnenmacher, Y. \& Hiller, K. Biochemistry of proinflammatory macrophage activation. Cell Mol. Life Sci. 75, 2093-2109 (2018).

40. Li, P. Z., Li, J. Z., Li, M., Gong, J. P. \& He, K. An efficient method to isolate and culture mouse Kupffer cells. Immunol. Lett. 158, 52-56 (2014).

41. Atanasov, A. G. et al. Cell cycle-dependent regulation of extra-adrenal glucocorticoid synthesis in murine intestinal epithelial cells. FASEB J. 22, 4117-4125 (2008).

42. Jakob, S., Corazza, N., Diamantis, E., Kappeler, A. \& Brunner, T. Detection of apoptosis in vivo using antibodies against caspase-induced neo-epitopes. Methods 44, 255-261 (2008) 